\title{
Demographic, Life Style and Job-Related Determinants of Quality of Life of Industrial Manufacturing Employees: An Application of Multilevel Latent Class Regression on a Large Cross-Sectional Study
}

\author{
Najmeh Rabanipour ${ }^{1}$, Hamidreza Roohafza ${ }^{2}$, Awat Feizi ${ }^{1,2 *}$, Nizal \\ Sarrafzadegan $^{3}$
}

\section{OPEN ACCESS}

Citation: Najmeh Rabanipour, Hamidreza Roohafza, Awat Feizi, Nizal Sarrafzadegan. Demographic, Life Style and Job-Related Determinants of Quality of Life of Industrial Manufacturing Employees: An Application of Multilevel Latent Class Regression on a Large CrossSectional Study. Ethiop J Health Sci. 2018;29(1):847.

doi:http://dx.doi.org/10.4314/ejhs.v29i1.6

Received: April 14, 2018

Accepted: July 11, 2018

Published: January 1, 2019

Copyright: (C) 2018 Najmeh R., et al. This is an open access article distributed under the terms of the Creative Commons Attribution License, which permits unrestricted use, distribution, and reproduction in any medium, provided the original author and source are credited.

Funding: Isfahan University of Medical Sciences.

Competing Interests: The authors declare that this manuscript was approved by all authors in its form and that no competing interest exists.

Affiliation and Correspondence:

${ }^{1}$ Department of Biostatistics and Epidemiology, School of health, Isfahan University of Medical Sciences, Isfahan, Iran

${ }^{2}$ Cardiac Rehabilitation Research Center, Cardiovascular Research Institute, Isfahan University of Medical Sciences, Isfahan, Iran

${ }^{3}$ Isfahn Cardiovascular Research Center, Cardiovascular Research Institute, Isfahan University of Medical Sciences, Isfahan, Iran

*Email: awat_feiz@hlth.mui.ac.ir

\section{ABSTRACT}

BACKGROUND: Employees are one of the key elements of an organization and measure the quality of life $(Q \circ L)$ provides reliable assessment of health and wellbeing in this population. This study aimed at investigating the QoL in a large sample of Iranian industrial manufacturing employees and its determinants.

METHODS: In a cross-sectional study conducted was in 2015, 3063 people were selected among 16000 Esfahan Seal Company's employees using multistage cluster sampling. QoL was evaluated by EQ-5D questionnaire, mental health by GHQ-12, physical activity by IPAQ, job stress by Effort-Reward Imbalance questionnaire. Self-report questionnaire was used for gathering demographic characteristics. Multilevel latent class regression analysis was used for data analysis using $R$ (3.4.3).

RESULTS: The mean (SD) age of the study participants was 36.74 (7.31), and $91.5 \%$ of them were males. The mean (SD) sleep duration was 7.11 (1.17), and 95.4\% of the participants had normal mental health. Latent class analysis classified employees into two classes (high (82.4\%) and low QoL (17.6\%)). Also employees' job categories classified into high and low QoL classes $(79.55 \%$ and $20.45 \%$, respectively). Latent class regression showed that lower age $(O R=0.93 ; P<0.0001)$, being male $(O R=1.75 ; p=0.009)$, lower levels of education $(O R=2.1 ; P<0.0001)$, normal mental health $(O R=12.4 ; P<0.0001)$, higher sleep duration $(O R=1.2 ; P<0.0001)$ and lower $B M I(O R=0.96 ; P=0.016)$ were significant predictors of being in high QoL class.

CONCLUSION: Our study provides data about the QoL of industrial manufacturing employees along with its significant determinants. The findings picture the ways for improving QoL, finally increasing the efficiency and productivity of workforce by directing health policies appropriately.

KEYWORDS: Quality of Life, Lifestyle, Job-Related Factors, Manufacturing Employees, Latent Class Analysis 


\section{INTRODUCTION}

The concept of quality of life (QoL) refers to the physical, mental, social and spiritual dimensions of a person's wellbeing (1). Evaluation QoL provides useful information about how persons realize their lives, afford to or overcome difficulties (healthrelated or not). Finally, how they are able to become stable and succeed despite difficulties (2).

Employees are one of the key success elements of an organization and also health and wellbeing are important in this population. Hence, it is necessary to evaluate the QoL as an important indicator of health among work force in the all organizations. Manufacturing employees are exposed to occupational risks which affecting QoL (3).

It is believed that a number of factors might influence QoL. Demographic factors such as lower age, being male, higher educational attainments, married people and the increased number of family members are most important determinants for high QoL(4-6). It is well known that life style factors (such as higher sleep duration, higher physical activity, lower BMI and normal mental health) are mostly associated with higher QoL (79 ). In this regard, previous studies showed that jobrelated variables such as job stress levels, shift worker and having second job may also affect QoL(10-12).

The majority of previous studies on QoL focused on patients $(13,14)$, general (15) and specific occupational populations in the world as well as in Iran $(16,17)$. QoL has been rarely investigated comprehensively among manufacturing industrial employees $(18,19)$.

On the other hand, most of the previous studies on QoL have applied descriptive and simple statistical analyses. QoL was investigated as a single measure and in particular, its latent nature was not consider. QoL is a multidimensional concept which evaluates the different aspects of wellbeing including mobility, self-care, daily activities, pain, and emotional wellbeing. It is thus necessary to use an advanced statistical method for evaluating it comprehensively. Latent class analysis provides a comprehensive evaluation of QoL of participants by classifying them based on all five domains simultaneously. In this study, we used multilevel latent class (MLC) analysis to assess QoL in a large sample of Iranian manufacturing industrial employees. This method provides a comprehensive feature about the QoL of employees by classifying them based on QoL in a multilevel setting in which manufacturing employees as lower units are nested in job categories as higher units. This model, in its regression framework enabeled us to investigate the association between QoL and its demographic, life style and job-related determinants. Furthermore, in a multilevel setting, job categories, as higher-level units, are also classified in terms of QoL.

\section{METHODS}

Study design and sample: We did a crosssectional study, in 2015 among 16,000 formal and contractual manufacturing employees of Esfahan Steal Company (ESC). All employees with at least one year of work experience and agreement to participate were included in the study. Participants who did not answer to several questions (more than $10 \%$ of the questionnaires' pages) were excluded from analysis. Multi-stage cluster sampling, along with stratified random sampling, was used to select participants based on the number of managerial departments and the number of employees who worked in each section. Because of the random nature of sampling and the limited number of female employees, 260 volunteer females were intentionally included in the study to have a sufficient sample size of females. Therefore, 3063 participants were finally entered in the statistical analysis. The study protocol was approved by the Medical Research Ethics Committee of the Cardiovascular Research Institute (Research project number: 87115), and written informed consent was obtained from all participants.

Study instruments: EuroQol-5D questionnaire (EQ-5D)- EQ-5D is a standardized and generic measure of QoL that can be used both in healthy populations and different groups of illnesses. It contains two parts: a self-reported description and a self-rated evaluation. The self-reported description assesses five dimensions of health: mobility, self-care, usual activity, pain/discomfort and anxiety/depression. These dimensions are rated

DOI: http://dx.doi.org/10.4314/ejhs.v29i1.6 
by respondents on a three-point scale (no problem, moderate problem and extreme problem), according to their own health on the day of the survey. The self-rated evaluation uses a visual analogue scale (VAS) in which respondents are asked to rate a state of ill-health on a scale from 0 to 100 , producing an EQ-5D index score (20).

This questionnaire has good validity and reliability. For example, Brazier J et al. showed a reliability index of between 0.77 and 0.88 in their studies (21). This study used the Iranian value set for EQ-5D health states in order to calculate participants' QoL. This value set was derived using the visual analog scale method (VAS) $(22,23)$.

Mental health questionnaire (GHQ-12): The GHQ-12 was used to assess mental health of study participants. It consists of 12 questions including focusing, being useful, enjoying life, confronting problems, depression, life satisfaction, worrying, decision making, constant pressure, overcoming problems, self-confidence and worthlessness. Every one of its 12 items regarding recent symptoms, feelings or behaviors is answered on a four-category Likert scale (Too usual, in the usual range, less than usual and much less than usual). Categories 1 and 2 are given value 0 , and categories 3 and 4 are given value 1 . Values from 12 items are added together to get an overall score. The score of the questionnaire varies from zero (favorable condition) to 12 (unfavorable condition), and a probable psychiatric case is considered when the score is equal to or greater than 4 (24). Montazeri et al. reported that the Cronbach's alpha coefficient of the questionnaire was 0.87 (25).

Job stress questionnaire: The Effort-Reward Imbalance (ERI) questionnaire, developed by Siegrist, measures effort, reward and overcommitment, to determine whether ERI and overcommitment are present. The questionnaire consists of 23 questions, indicating an effort and reward imbalance, and has three scales of effort (6 questions), reward (11 questions) and over commitment (6 questions). ER $<1$ indicates an imbalance in favor of rewards and ER $>1$ indicates an imbalance in favor of effort (26). The reliability of this questionnaire was studied by Yadgarfer et al., and the Cronbach's alpha coefficients for attempts, rewards and commitments were reported to be $0.61,0.85$ and 0.67 , respectively (27).

Physical activity questionnaire: Physical activity was evaluated by the International Physical Activity Questionnaire (IPAQ), which included 11 questions. The reliability of this questionnaire was studied by Moghaddam et al. who reported the Cronbach's alpha coefficient of the questionnaire as 0.7, and the Spearman Brown correlation coefficient (0.9) showed good internal consistency and test retest reliability (28).

Sociodemographic, life style and job-related variables: In this research, the other determinates of QoL included age (year), gender (male/female), marital status (married/single), number of family members (number), education (0-5 years/6-12 years/over 12 years), sleep duration (hours), physical activity (hour per week), BMI $\left(\mathrm{kg} / \mathrm{m}^{2}\right)$, mental health (normal/abnormal), job stress (imbalance effort-reward), shift work (daily/ rotational) and having second job (yes/no).

Statistical analysis: In this study, a latent class analysis (LCA) was used to empirically extract homogeneous latent classes of employees based on their responses to 5 health-related quality of questions. The multilevel latent class (MLC) model extends the traditional latent class (LC) framework to a multilevel setting. In this study, employees were nested in job categories and MLC model extracted the categorical latent variables for both employees and job categories; i.e. both employees and their job categories are classified in terms of QoL. In this model, employees' LCs and nesting within job categories were first extracted, and then the job categories as higher level units were classified based on manufacturing employees' QoL. Because our LC indicators (5 domains of QoL) were discrete, we used a nonparametric estimation which leads to classification of higher level units i.e. job categories. Our rationale for using MLC is that this approach allows us to explore more substantively meaningful classification of job categories in terms of QoL. The primary benefit of MLC, is that not only the classes of employees generated, but also classes of job categories based on the employees classes were generated(29,30). In the regression framework of this modeling approach, we were also able to evaluate the determinant of QoL.

DOI: http://dx.doi.org/10.4314/ejhs.v29i1.6 
Furthermore, to determine the number of latent classes, we evaluated model fit criteria including Akaike's information criterion (AIC), Baysian information criterion (BIC), the adjusted Bayesian information criterion (ABIC) and entropy.

Quantitative variables were expressed as mean \pm standard deviation and qualitative variables as frequency (percentages). Quantitative variables were compared between QoL class using independent t-test and categorical variables using Chi-square test. Latent class analysis was employed using R (3.4.3) free software.

\section{RESULTS}

Sample characteristics: Table 1 presents descriptive findings of the 3063 Esfahan Steal
Company's Industrial Manufacturing employees. The mean age was 36.74 years $(\mathrm{SD}=7.31), 91.5 \%$ were male, $90 \%$ were married, most of the employees $(62.3 \%)$ educated between $6-12$ years and mean number of family members was 3.6 $(\mathrm{SD}=1.1)$. Almost all of the employees $(95.4 \%)$ had normal mental health score and the mean sleep duration and physical activity were 7.11 hour (SD $=1.17)$ per day and 7.33 hours per week $(\mathrm{SD}=3.65)$ respectively. There was an imbalance in favor of rewards of employees, because the mean job stress was 0.67 . In this study, $54.9 \%$ of employees had rotational work and $90.7 \%$ of them did not have second job.

Table1: Characteristics of industrial employees $(n=3063$ nested in 71 job categories $)$ in Isfahan Steal Company

\begin{tabular}{ll}
\hline variables & $\begin{array}{l}\text { Mean } \pm \text { SD or } \\
\text { frequency(percentage) }\end{array}$ \\
Age (year) & $36.74 \pm 7.31$ \\
Sex & \\
Male & $2803(91.5)$ \\
Female & $260(8.5)$ \\
Marital status & \\
$\quad$ Married & $2758(90)$ \\
Single & $305(10)$ \\
number of family members & $3.6 \pm 1.1$ \\
Education years & \\
0-5 year & $255(8.3)$ \\
6-12 year & $1908(62.3)$ \\
> 12 year & $900(29.4)$ \\
Mental health & $0.61 \pm 1.3$ \\
Normal & $2921(95.4)$ \\
Abnormal & $140(4.6)$ \\
Sleep duration (hour) & $7.11 \pm 1.17$ \\
Physical activity (hour per weak) & $7.33 \pm 3.65$ \\
BMI (kg) & $25.6 \pm 3.8$ \\
Job stress (ERI) & $0.67 \pm 0.22$ \\
Shift work & \\
Daily & $1380(45.1)$ \\
Rotational & $1683(54.9)$ \\
Second job & \\
Yes & $285(9.3)$ \\
No & $2778(90.7)$ \\
\hline
\end{tabular}

DOI: http://dx.doi.org/10.4314/ejhs.v29i1.6 
Classification of participants based on QoL: We estimated a series of LCA models to determine the number of latent classes (2-5 latent classes) at the employees level. All models' fit criteria as well as interpretability of extracted classes strongly suggested an LCA model with two employees' latent classes based on five dimensions of EQ-5D.

Table 2 reports the 2-class solution of employees in terms of QoL, the largest class represents high QoL and comprises $82.4 \%$ of the study samples. As can be seen, the employees included in class 1 were most likely to report no or few problems in self-care and usual activity, and most of them did not have any problems in mobility, pain/discomfort and anxiety/depression.

The second class comprises participants with low QoL who constituted 17.6\% of the study samples. Employees in this class were most likely to report moderate/sever problem or severe pain/discomfort and moderate anxiety/depression.

Table 2: Item-Response Probability for each EQ-5D Questions for two Class Model

\begin{tabular}{lllll}
\hline Class size & No problem & $\begin{array}{c}\text { Class 1 } \\
\mathbf{8 2 . 4 \%} \\
\text { high QoL }\end{array}$ & Moderate/ Sever & \multicolumn{2}{c}{$\begin{array}{c}\text { Class 2 } \\
\mathbf{1 7 . 6 \%} \\
\text { low QoL }\end{array}$} \\
\hline Indicator & No problem & Moderate/Sever \\
\hline Mobility & 0.99 & 0.01 & 0.69 & 0.31 \\
\hline Self-care & 1 & 0 & 0.99 & 0.01 \\
\hline Usual Activity & 1 & 0 & 0.94 & 0.06 \\
\hline Pain/Discomfort & 0.95 & 0.05 & 0.13 & 0.87 \\
\hline Anxiety/Depression & 0.89 & 0.11 & 0.48 & 0.52 \\
\hline
\end{tabular}

After classifying participants in terms of QoL using LCA, a univariate analysis was done to compare characteristics of the industrial manufacturing employees between classes (Table 3 ). The results showed that age, sex, number of family members, education, mental health, sleep duration, physical activity, BMI and shift work were significantly different between two classes. In more details, $92.6 \%$ of males, $98.4 \%$ of employees with normal mental health and $57 \%$ of rotational workers had high QoL. Also, the mean age in the high QoL class was lower (36.24 year), indicated that increase in age reduced the QoL. In the high QoL class, mean sleep duration (7.18 hour) is higher than low QoL class. Therefore, increase in sleep duration leads to increase the QoL. Increasing BMI, reduces the QoL because in the low QoL class, mean BMI is higher than high QoL class.
In order to classify the employees' job categories, as higher levels units that employees were nested in, in terms of QoL, we then extended the twoclass LCA model to multilevel setting. In sum, the final multilevel latent class the model led to two employee latent classes and two latent classes from employees' job categories.

Figure 1 shows the results of final model, and it pictures how the employees' classes distributed among across the two classes of job categories. Those employees' job categories that included higher portion of employees with high QoL were labeled as high QoL class; Class1 $(79.55 \%$ of job categories, included $81.8 \%$ and $18.2 \%$ of employees with high and low QoL, respectively) and $20.45 \%$ job categories were classified as Low QoL. 
Table 3: Univariate association between characteristics of the industrial employees and QoL

\begin{tabular}{|c|c|c|c|}
\hline variables & $\begin{array}{l}\text { Class 1 } \\
\text { (high QoL)* }\end{array}$ & $\begin{array}{l}\text { Class 2 } \\
\text { (low QoL)* }\end{array}$ & p-value ** \\
\hline Age (year) & $36.24 \pm 7.3$ & $38.83 \pm 7.5$ & $<0.0001$ \\
\hline Sex & & & $<0.0001$ \\
\hline Male & $2648(92.6)$ & $115(86.7)$ & \\
\hline Female & $231(7.4)$ & $28(13.3)$ & \\
\hline Marital status & & & 0.3 \\
\hline Married & $2597(89.8)$ & $282(90.9)$ & \\
\hline Single & $124(10.2)$ & $19(9.1)$ & \\
\hline Number of family members & $3.6 \pm 1.1$ & $3.8 \pm 1.1$ & $<0.0001$ \\
\hline Education years & & & 0.008 \\
\hline $0-5$ year & $245(8.9)$ & $8(6.01)$ & \\
\hline $6-12$ year & $1805(62.9)$ & $80(60.35)$ & \\
\hline$>12$ year & $829(28.2)$ & $55(33.64)$ & \\
\hline Mental health & & & $<0.0001$ \\
\hline Normal & $2871(98.4)$ & $50(82.8)$ & \\
\hline Abnormal & $6(1.6)$ & $134(17.2)$ & \\
\hline Sleep duration (hour) & $7.18 \pm 1.15$ & $6.8 \pm 1.3$ & $<0.0001$ \\
\hline Physical activity (hour per weak) & $7.22 \pm 3.6$ & $7.8 \pm 3.9$ & $<0.0001$ \\
\hline BMI (kg) & $25.43 \pm 3.79$ & $26.24 \pm 3.81$ & $<0.0001$ \\
\hline Job stress (ERI) & $0.66 \pm 0.22$ & $0.67 \pm 0.26$ & 0.2 \\
\hline Shift work & & & $<0.0001$ \\
\hline Daily & $1278(43)$ & $81(53)$ & \\
\hline Rotational & $1601(57)$ & $62(47)$ & \\
\hline Second job & & & 0.7 \\
\hline Yes & $270(94.8)$ & $13(8.9)$ & \\
\hline No & $2609(90.5)$ & $130(91.1)$ & \\
\hline
\end{tabular}

*Quantitative variables were expressed as mean \pm standard deviation and qualitative variables as frequency (percentage). ${ }^{* *}$ using t-test and Chi-square test.

Determinants of QoL: Table 4 displays the results of the multilevel latent class regression (MLCR) to determine the predictive role of demographic, life style and job determinants for employees' QoL class membership. It appears that age, sex, education status, mental health, sleep duration and BMI significantly predict class membership. More specifically, one-year increase in age decreases $7 \%$ odds of beings in high QoL class, i.e. increase in age lead to decrease QoL $(\mathrm{OR}=0.93 ; 95 \% \mathrm{CI}: 0.91-0.94)$. Also, males were 1.75 times more likely to be in high QoL class than females; males have higher QoL $(\mathrm{OR}=1.75$; 95\%CI: 1.5-3). Surprisingly, higher education reduced QoL because the odds of being in the high QoL class for employees with 0-5 education years were 2.1 times higher than employees with education years more than 12 years $(\mathrm{OR}=2.1$; 95\%CI: 1.3-3.6). Likewise, one hour increase in sleep duration, increases $20 \%$ odds for being in high QoL class $(\mathrm{OR}=1.2 ; 95 \% \mathrm{CI}: 1.2-1.4)$. The odds of being in the high QoL class was 12.4 times higher among employees with normal mental health than employees with abnormal mental health; employees with normal mental health had higher QoL (OR=12.4; 95\%CI: 12.128.8). One unit increase in BMI, decreases $4 \%$ odds for beings in high QoL class $(\mathrm{OR}=0.94$; 95\%CI: 0.93-0.98).

DOI: http://dx.doi.org/10.4314/ejhs.v29i1.6 


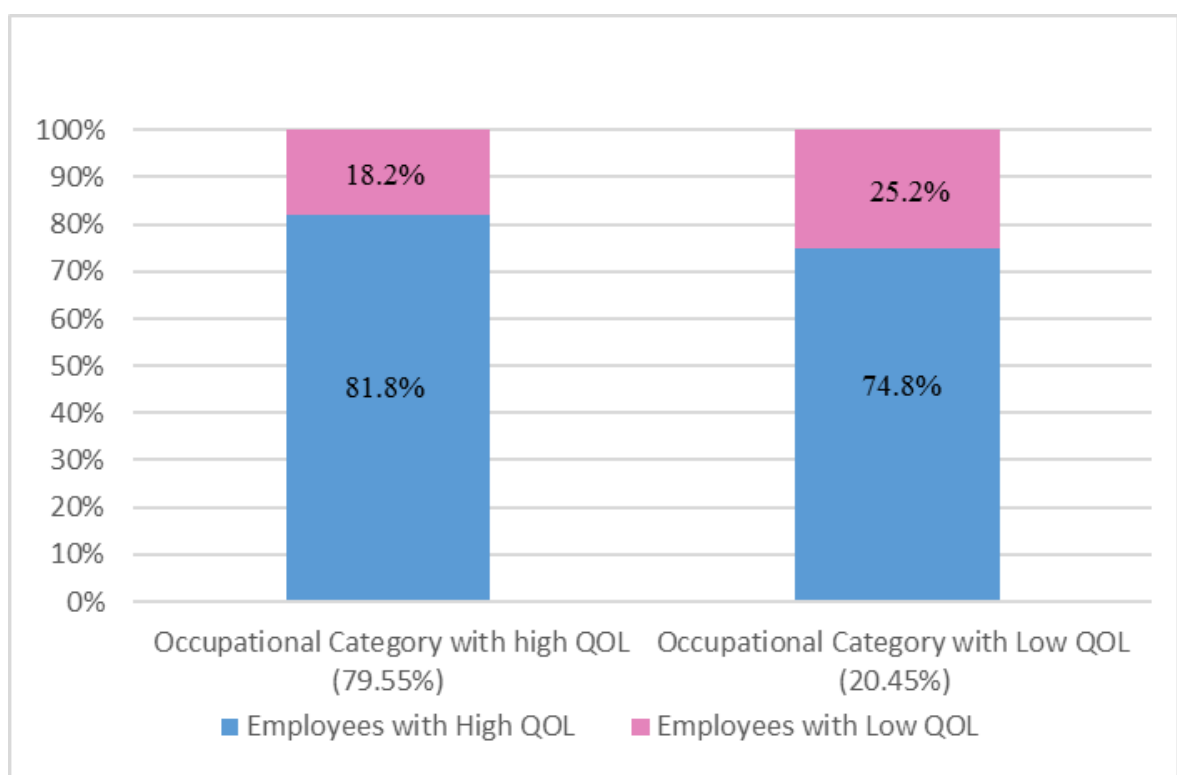

Figure 1: Distribution of employee's latent classes ( $\mathrm{n}=3063$ employees) within job categories latent classes $(\mathrm{n}=71$ job categories)

Table 4: Multivariable Odds ratio (OR) and 95\% CI for OR of the association between demographic, life style and job related variables with high QoL class membership

\begin{tabular}{|c|c|c|c|}
\hline Determinants of QoL & $O R^{*}$ & $\mathbf{9 5} \% \mathbf{C I}^{* *}$ & p-value \\
\hline Age (year) & 0.93 & $0.91-0.94$ & $<0.0001$ \\
\hline \multicolumn{4}{|l|}{ Sex } \\
\hline Male & 1.75 & $1.5-3$ & 0.009 \\
\hline Female & 1 & - & - \\
\hline \multicolumn{4}{|l|}{ Marital status } \\
\hline $\begin{array}{l}\text { Married } \\
\text { Single }\end{array}$ & 1.2 & $0.84-2$ & 0.5 \\
\hline number of family members & 0.97 & $0.88-1.1$ & 0.7 \\
\hline Education years & & & 0.03 \\
\hline $0-5$ year & 2.1 & $1.3-3.6$ & \\
\hline $6-12$ year & 1.1 & $0.7-1.2$ & \\
\hline$>12$ year & 1 & - & \\
\hline \multicolumn{4}{|l|}{ Mental health } \\
\hline Normal & 12.4 & $12.1-28.8$ & $<0.0001$ \\
\hline Abnormal & 1 & - & \\
\hline Sleep duration (hour) & 1.2 & $1.2-1.4$ & $<0.0001$ \\
\hline Physical activity (hour per weak) & 0.97 & $0.94-1$ & 0.096 \\
\hline BMI $\left(\mathrm{kg} / \mathrm{m}^{2}\right)$ & 0.96 & $0.93-0.98$ & 0.016 \\
\hline Job stress (ERI) & 0.87 & $0.5-1.3$ & 0.63 \\
\hline \multicolumn{4}{|l|}{ Working shift } \\
\hline Daily & 0.86 & $0.66-1.04$ & 0.26 \\
\hline Rotational & & & \\
\hline \multicolumn{4}{|l|}{ Second job } \\
\hline Yes & 1.06 & $0.67-1.4$ & 0.56 \\
\hline No & & & \\
\hline
\end{tabular}

*OR= odds ratio. ${ }^{* *} \mathrm{CI}=$ confidence interval, the presented ORs shows the impacts of each variable for being in good QoL class, resulted from MLCR

DOI: http://dx.doi.org/10.4314/ejhs.v29i1.6 


\section{DISCUSSION}

Our study investigated the QoL in a large sample of Iranian industrial manufacturing employees. MLCR classified employees and their job categories based on QoL items as well as a wide range of demographic, life style and job-related determinants of QoL.

In recent years, interest in measuring QoL has increased to provide an additional and more accurate assessment of individuals or populations' health and wellbeing. The results of QoL may come from specific health interventions (31). QoL is usually determined by a complex interaction of sociocultural, psychological, environmental and demographic factors (32).

Our findings showed that a high proportion of study participants had high QoL, and that some demographic and life style variables were significant predictors for high QoL. In this study, we identified that mental health, sleep duration, age, sex, education years and BMI are significant predictors of employee QoL's latent class membership. Some previous studies have reported that many factors affect QoL among industrial manufacturing employees. For instance, Malakeh et al. (2017) in a study on 640 industrial workers, using Spearman's correlation, concluded that there were statistically significant positive relationships between educational level, physical activity and family life with QoL. Also, negative relationships were documented between age, quality of sleep, BMI, job tenure and working hours with QoL (33). Likewise, Mokarami et al. (2016) investigated the impacts of psychosocial and physical work-related factors on the QoL among 280 Iranian industrial workers, by hierarchical multiple regression. They revealed that social support, sleep quality, work schedule, smoking and exercise were significant predictors of all QoL's domains (34).

QoL is influenced by various physical and mental factors, and previous studies showed that psychological wellbeing is a key determinant of QoL and abnormal mental health affects QoL(35). Abnormal mental health (depression, anxiety, stress) causes negative feelings on person's life and influences the QoL while positive aspects of mental health (feel calm, contented, relaxed, happiness) improve sociological aspects of a person and thus improve QoL (36). In accordance with the earlier studies, our results showed that abnormal mental health is the most important factor for low QoL among all the studied QoL's determinants. Mathew G et al. (2016) conducted a study on QoL among men workers and concluded that mental health has a significant impact on QoL (37).

Sleep duration can play a vital role in QoL. As an important biological function, sleep duration plays a role in various physiological processes of organs. Appropriate sleep provides the basis for physical, mental and psychological wellbeing in humans, and inappropriate sleep is associated with less productive behavior (38). Hence, QoL is primarily influenced by sleep duration. To improve the QoL, employees should develop a good daily routine and should have sufficient sleep after work. In accordance with our finding on the association of sleep duration with QoL, previous studies indicated that the better the sleep quality, the better QoL $(39,40)$. Palhares et al. (2014) in a study on nursing professionals by logistic regression analysis identified that QoL and quality of sleep were closely correlated (41).

Increase in age leads to reduced physical and mental capabilities. This decline was more in physical health, but has also been detected in the mental health scales. Anxiety and depression scores increased with age. However, existential and supportive well-being decreased with age, thus increase in age lead to decrease QoL (42). In addition, physical abilities become weaker in older workers, and several health difficulties can limit older people's ability at work (43). Accordingly, our data clearly indicate that employees with lower age had increased odds for being in the high QoL class. These findings are supported by previous studies which indicated that increasing age reduces QoL. In accordance with our results, Liu et al. (2017), in their study on workers and farmers, concluded that increasing age was associated with poor QoL (44).

Regarding the two employees' latent classes, we found that males showed higher odds for being in the category of high QoL. Furthermore, several studies have reported that males are more likely, than females, to experience high QoL $(10,45)$. For

DOI: http://dx.doi.org/10.4314/ejhs.v29i1.6 
instance, in Ioannou's study on 508 Greek nurses, using multivariate linear regression analysis showed that men had higher physical and mental QoL than women (46). Although systematic difference in QoL between males and females is a common finding, very few explanations or interpretations have been presented. Farlinger, focusing on women's QoL, explained that women are more affected by severe job conditions, have a more sensitive mood, and experience excess physical complaints which begins in pregnancy. Therefore, their QoL is lower than that of males. (47). Considering the scarce evidence in this regard, more research is needed not only to determine gender differences in QoL, but also to identify the consequences they involve.

Improving the education and analytical skills of individuals led to feeling relatively healthier but may cause stress and depression, so balance in education have positive effects on QoL (48). Almost all of the previous studies on QoL indicated that increasing education years led to increasing QoL(49,50). Although, based on our results, employees with lower educational attainments had higher QoL, such findings are scarce.

The relationship between BMI and QoL is potentially examined by complex biological and social frameworks. Unhealthy weight is a wellknown risk factor for many physical and mental disorders, thus causes a reduction in QoL (51). Our study identified the effect of BMI on QoL in which employees with high BMI had low QoL. These findings are supported by the negative association between BMI and QoL documented in past studies. In line with our results, Cash (2012), in a study on 747 employees by linear mixed models, confirmed that BMI was negatively associated with higher QoL (52).

In our study, job-related variables were not significant predictors of QoL, but some studies showed significant relationships. Kaliterna and et al. (2014) investigated the quality of life in 311 night-shift workers, 207 shift workers without night shifts and 1210 non-shift workers, They concluded that QoL in night-shift workers was rated worse than in other groups of workers (53). Kittipichai et al. (2015) investigated the factors influencing the quality of life among 205 Thai workers, by stepwise multiple regression analysis. The results revealed that QoL was significantly associated with co-worker relationships, safety at work in the dimension of accident prevention and job characteristics (54).

It is important to recognize some strengths and potential limitations of this study. The study can be considered as one of the few studies globally and the first comprehensive study to investigate the effect of demographic, life style and job-related determinants of QoL among a large sample of industrial manufacturing employees in Iran. We used an advanced statistical model, i.e., multilevel latent class regression. This advanced statistical method provides a comprehensive assessment of QoL by classifying employees and their job categories that are nested in objectively and simultaneously analyzed the wide varieties of determinants of QoL. However, our study has some limitations. It is a cross-sectional study in which causal inference cannot be made from the significant associations obtained. Also, the questionnaire was self-reported that may affect the validity of the results and the classification of participants.

In summary, our study provides pertinent and valuable information about measuring QoL and its significant determinants among industrial manufacturing employees in a developing country. Relatively high proportion of employees reported low QoL. Our study signified the important roles of some demographic, life style and job-related variables on QoL of industrial employees. Therefore, these findings picture the ways for improving QoL and increasing the productivity of workforce by directing health policies appropriately.

\section{REFERENCES}

1. Michalos AC. Social indicators research and health-related quality of life research. In: Connecting the Quality of Life Theory to Health, Well-being and Education. Springer; 2017. Volume 65, p. 25-58.

2. Bowling A. Measuring Health: A Review of Subjective Health, Well-being and Quality of Life Measurement Scales. Open University

DOI: http://dx.doi.org/10.4314/ejhs.v29i1.6 
Press; 2017, 360pp.

3. Rongen A, Robroek SJW, van Lenthe FJ, Burdorf A. Workplace health promotion: a meta-analysis of effectiveness. Am J Prev Med. 2013;44(4):406-15.

4. Qin J, Liu W, Zhu J, Weng W, Xu J, Ai Z. Health related quality of life and influencing factors among welders. PLoS One. 2014;9(7):1-8.

5. Roswall N, Høgh V, Envold-Bidstrup P, Raaschou-Nielsen O, Ketzel M, Overvad K, et al. Residential exposure to traffic noise and health-related quality of life-a populationbased study. PLoS One. 2015;10(3): 0120199.

6. Hipp M, Pilz L, Al-Batran SE, Hautmann MG, Hofheinz R-D. Workload and quality of life of medical doctors in the field of oncology in Germany-a survey of the Working Group Quality of Life of the AIO for the Study Group of Internal Oncology. Oncol Res Treat. 2015;38(4):154-9.

7. Wu M, Zhao Y, Wang R, Zheng W, Guo X, $\mathrm{Wu} \mathrm{S}$, et al. Epidemiology of Functional Abdominal Bloating and Its Impact on Health Related Quality of Life: Male-Female Stratified Propensity Score Analysis in a Population Based Survey in Mainland China. PLoS One. 2014;9(7):e102320.

8. Fernandes-Junior SA, Ruiz FS, Antonietti LS, Tufik S, de Mello MT. Sleep, fatigue and quality of life: A comparative analysis among night shift workers with and without children. PLoS One. 2016;11(7): 0158580.

9. Alexopoulos EC, Palatsidi V, Tigani X, Darviri C. Exploring stress levels, job satisfaction, and quality of life in a sample of police officers in Greece. Saf Health Work. 2014;5(4):210-5.

10. Soltysik BK, Kroc L, Piglowska M, Guligowska A, Smigielski J, Kostka T. An Evaluation of the Work and Life Conditions and the Quality of Life in 60 to 65 Year-Old White-Collar Employees, Manual Workers, and Unemployed Controls. J Occup Environ Med. 2017 May;59(5):461-6.

11. Malamardi SN, Kamath R, Tiwari R, Nair BVS, Chandrasekaran V, Phadnis S.
Occupational stress and health-related quality of life among public sector bank employees: A cross-sectional study in Mysore, Karnataka, India. Indian $J$ Occup Environ Med. 2015;19(3):134-7.

12. Kawabe Y, Nakamura Y, Kikuchi S, Suzukamo Y, Murakami Y, Tanaka T, et al. Relationship of type of work with healthrelated quality of life. Qual Life Res. 2015;24(12):2927-32.

13. Artigas NR, Striebel VLW, Hilbig A, Rieder CR de M. Evaluation of quality of life and psychological aspects of Parkinson's disease patients who participate in a support group. Dement Neuropsychol. 2015;9(3):295-300.

14. Opoku-Boateng YN, Kretchy IA, Aryeetey GC, Dwomoh D, Decker S, Agyemang SA, et al. Economic cost and quality of life of family caregivers of schizophrenic patients attending psychiatric hospitals in Ghana. BMC Health Serv Res. 2017 Dec;17(Suppl 2):697.

15. Koohi F, Nedjat S, Yaseri M, Cheraghi Z. Quality of Life among General Populations of Different Countries in the Past 10 Years, with a Focus on Human Development Index: A Systematic Review and Meta-analysis. Iran J Public Health. 2017 Jan;46(1):12-22.

16. Cakmakci Karadogan D, Onal O, Say Sahin D, Yazici S, Kanbay Y. Evaluation of school teachers' sociodemographic characteristics and quality of life according to their cigarette smoking status: a cross-sectional study from the eastern Black Sea region of Turkey. Tuberk Toraks. 2017 Mar;65(1):18-24.

17. Roustaei N, Jamali H, Jamali MR, Nourshargh P, Jamali J. The Association Between Quality of Sleep and Health-related Quality of Life in Military and Non-military Women in Tehran, Iran. Oman Med J. 2017 Mar;32(2):130-4.

18. Kabir-Mokamelkhah E, Bahrami-Ahmadi A, Aghili N. Work-related stress and quality of life among Iranian blue-collar workers with self-reported low back pain. Med J Islam Repub Iran. 2016;30:474.

19. Mohammadi H, Dehghan SF, Golbabaei F, Roshani S, Pakzad R, Foroughi $\mathrm{P}$, et al. Pulmonary Functions and Health-Related

DOI: http://dx.doi.org/10.4314/ejhs.v29i1.6 
Quality of Life among Silica-Exposed Workers. Tanaffos. 2017;16(1):60-7.

20. Theofilou P. Quality of life: definition and measurement. Eur J Psychol. 2013;9(1):150.

21. Brazier J, Jones N, Kind P. Testing the validity of the Euroqol and comparing it with the SF-36 health survey questionnaire. Qual Life Res. 1993;2(3):169-80.

22. Rezaei S, Hajizadeh M, Kazemi A, Khosravipour M, Khosravi F, Rezaeian S. Determinants of health-related quality of life in Iranian adults: Evidence from a crosssectional study. Epidemiol Health. 2017 Aug;

23. Goudarzi R, Zeraati H, Akbari Sari A, Rashidian A, Mohammad K. PopulationBased Preference Weights for the EQ-5D Health States Using the Visual Analogue Scale (VAS) in Iran. Iran Red Crescent Med J. 2016;18(2).

24. Goldberg DP, Williams P. A User's Guide to the General Health Questionnaire: GHQ (Windsor, Nelson). 350 A Guppy and] Marsden. 1988;

25. Montazeri A, Harirchi AM, Shariati M, Garmaroudi G, Ebadi M, Fateh A. The 12item General Health Questionnaire (GHQ12): translation and validation study of the Iranian version. Health Qual Life Outcomes. 2003;1(1):66.

26. Siegrist J, Li J, Montano D. Psychometric properties of the effort-reward imbalance questionnaire. Duesseld Univ Dep Med Sociol FoM. 2013; www.unikliniksuesseldorf.de/fileadmin/Datenpool/einrichtun gen/institut_fuer_medizinische_soziologie_id 54/ERI/Psychometrie.pdf.

27. Yadegarfar GH, Alinia T, Hassannezhad R, Fayaz M, Hosseini R, Sanati J, et al. Validation and Localization of Farsi Version of Effort-Reward Imbalance Questionnaire to Measure Job Stress among Employees of Isfahan Polyacryle Corporation. Iran $J$ Epidemiol. 2012;8(3):73-83.

28. Moghaddam MHB, Aghdam FB, Jafarabadi MA, Allahverdipour H, Nikookheslat SD, Safarpour S. The Iranian Version of International Physical Activity Questionnaire (IPAQ) in Iran: content and construct validity, factor structure, internal consistency and stability. World Appl Sci. 2012;18(8):107380.

29. Vermunt JK. Latent class and finite mixture models for multilevel data sets. Stat Methods Med Res. 2008;17(1):33-51.

30. Vermunt JK. 7. Multilevel Latent Class Models. Sociol Methodol. 2003;33(1):213-39.

31. Basu D. Quality-of-life issues in mental health care: Past, present, and future. Ger $J$ Psychiatry. 2004;7(3):35-43.

32. Massam BH. Quality of life: public planning and private living. Prog Plann. 2002;58(3):141-227.

33. Malak MZ. Predictors of health-related quality of life among industrial workers: A descriptive correlational study. Nurs Health Sci. 2017 Jun;19(2):204-11.

34. Mokarami H, Stallones L, Nazifi M, Taghavi SM. The role of psychosocial and physical work-related factors on the health-related quality of life of Iranian industrial workers. Work. IOS Press; 2016 Oct;55(2):441-52.

35. Dohrenwend BP, Shrout PE, Egri G, Mendelsohn FS. Nonspecific psychological distress and other dimensions of psychopathology: Measures for use in the general population. Arch Gen Psychiatry. 1980;37(11):1229-36.

36. Connell J, O'Cathain A, Brazier J. Measuring quality of life in mental health: are we asking the right questions? Soc Sci Med. 2014; 120:12-20.

37. Mathew G, Ramesh N, Shanbhag D, Goud R, Subramanian S, Lobo C, et al. Quality of life and probable psychological distress among male workers at a construction site, Kolar district, Karnataka, India. Indian J Occup Environ Med. 2016;20(1):54-9.

38. Goldstein AN, Walker MP. The role of sleep in emotional brain function. Annu Rev Clin Psychol. 2014;10:679-708.

39. Carey MG, Al-Zaiti SS, Dean GE, Sessanna L, Finnell DS. Sleep problems, depression, substance use, social bonding, and quality of life in professional firefighters. $J$ Occup Environ Med Coll Occup Environ Med. 2011;53(8):928.

40. Sonati JG, De Martino MMF, Vilarta R, da Silva Maciel E, Sonati RJF, Paduan PC.

DOI: http://dx.doi.org/10.4314/ejhs.v29i1.6 
Quality of Life, Sleep, and Health of Air Traffic Controllers With Rapid Counterclockwise Shift Rotation. Workplace Health Saf. 2016 Aug;64(8):377-84.

41. Palhares V de C, Corrente JE, Matsubara BB. Association between sleep quality and quality of life in nursing professionals working rotating shifts. Rev Saude Publica. 2014;48(4):594-601.

42. Netuveli G, Blane D. Quality of life in older ages. Br Med Bull. 2008;85(1):113-26.

43. Gharibi V, Mokarami H, Taban A, Aval MY, Samimi K, Salesi M. Effects of work-related stress on work ability index among Iranian workers. Saf Health Work. 2016;7(1):43-8.

44. Liu X, Gu S, Duan S, Wu Y, Ye C, Wang J, et al. Comparative Study on Health-Related Quality of Life of Farmers and Workers. Value Heal Reg issues. 2017 May;12:123-9.

45. Liu Y, Liu L, Sun W, Shan G-L, Wang Z-Z. [Survey on the quality of life and related factors among farmer workers in Hubei province]. Zhonghua Liu Xing Bing Xue Za Zhi.Europe PMC plus; 2011 May;32(5):481.

46. Ioannou $P$, Katsikavali V, Galanis P, Velonakis E, Papadatou D, Sourtzi P. Impact of Job Satisfaction on Greek Nurses' HealthRelated Quality of Life. Saf Health Work. 2015 Dec;6(4):324-8.

47. Farlinger S. Quality of life for women. Soc Indic Res. 1996;39(1):109-19.

48. Yildirim N, Karaca A, Cangur S, Acikgoz F, Akkus D. The relationship between educational stress, stress coping, self-esteem, social support, and health status among nursing students in Turkey: A structural equation modeling approach. Nurse Educ Today. 2017 Jan;48:33-9.

49. Liang Y, Wang H, Tao X. Quality of life of young clinical doctors in public hospitals in China's developed cities as measured by the Nottingham Health Profile (NHP). Int $J$ Equity Health. 2015;14(1):85.

50. Hong S, Jeong H, Heo Y, Chun H, Park J, Kim D. Factors associated with health-related quality of life in Korean older workers. Ann Occup Environ Med. 2015;27:25.

51. Kearns B, Ara R, Young T, Relton C. Association between body mass index and health-related quality of life, and the impact of self-reported long-term conditions-crosssectional study from the south Yorkshire cohort dataset. BMC Public Health. 2013;13(1):1009.

52. Cash SW, Beresford SAA, Henderson JA, McTiernan A, Xiao L, Wang CY, et al. Dietary and physical activity behaviours related to obesity-specific quality of life and work productivity: baseline results from a worksite trial. $\mathrm{Br} \quad \mathrm{J}$ Nutr. 2012 Sep;108(6):1134-42.

53. Kaliterna LLJ, Prizmic LZ, Zganec N. Quality of life, life satisfaction and happiness in shiftand non-shiftworkers. Rev Saude Publica. 2004;38:3-10.

54. Kittipichai W, Arsa R, Jirapongsuwan A, Singhakant C. Quality of Life Among Thai Workers in Textile Dyeing Factories. Glob $J$ Health Sci. 2015;7(3):274. 